\title{
Tuning of Proportional Derivative Control Parameters Base Particle Swarm Optimization for Automatic Brake System on Small Scale Wind Turbine Prototype
}

\author{
Ali Musyafa ${ }^{1}$, S. A. Pratama ${ }^{1} \&$ Ronny D. Nuriyati ${ }^{1}$ \\ ${ }^{1}$ Department of Engineering Physics, Faculty of Industrial Enginering, Sepuluh Nopember Institute of \\ Tehnology, Surabaya, Indonesia \\ Correspondence: Ali Musyafa, Department of Engineering Physics, Faculty of Industrial Enginering, Sepuluh \\ Nopember Institute of Tehnology, Surabaya, Indonesia. Tel: 62-031-596-6138. E-mail: musyafa@ep.its.ac.id \\ Received: September 24, 2014 \\ doi:10.5539/mas.v9n2p289
}

\begin{abstract}
In this paper the authors propose a method for tuning proportional derivative control parameters using the particle swarm optimizer for dynamic environments. The process consists of the brake system in wind turbine plant. Each particle to reset its record of its best position as the environment changes, to avoid making direction and velocity decisions on the basis of outdated information. In this study designed and implemented an automatic brake control system based Proportional-Derivative Particle Swam Optimization (PD-PSO). The goal is to maintain the reliability of the wind turbine generator, safety systems and the application of control systems in the system is more appropriate. Wind turbine rotation speed is detected using a rotary encoder to transmit data to the microcontroller and further control signals sent to the servo motor which serves to reduce the rotational speed of the wind turbine rotational. In this study the PD control mode parameters based on PSO, from the experiment for each parameter set points, among others when the set point in 5 pulse per second (PPS), have gain $\mathrm{Kip}=0.2812$ and $\mathrm{Kid}=1.2459$, maximum overshoot $=9 \%$ and error steady state $=2$ second. For set point 10 PPS, $\mathrm{Kp}=0.4738$ and $\mathrm{Kd}=0606$, maximum overshoot $=914 \%$ and error steady state $=2$ second. And last set point 15 PPS obtained parameter gain $\mathrm{Kp}=0.7147$ and $\mathrm{Kd}=2.0804$, maximum overshoot $=17 \%$ and error steady state $2 \%$ criterion $=2$ second.
\end{abstract}

Keywords: automatic brake control system, wind turbine, PD-PSO, pulse per second (PPS)

\section{Introduction}

\subsection{Introduce the Energy Crisis}

The energy crisis in Indonesia that reliance on fossil fuels is so big, so often discussed about the need for new alternative energy sources that can reduce environmental pollution which is used as a source of electrical energy. This is why humans began to search for new energy sources to replace the old energy source is fossil energy. The alternative energy has great potential renewable energy especially for wind energy is the wind has diverse benefits ranging from household goods, farm to power generation. But in Indonesia, wind energy received less attention because of the wind speed in Indonesia is always changing and has a relatively high speed that it is difficult in its processing. One of the benefits of the current turbine that has an important role for Indonesia, namely the application of wind turbines to generate electricity, but this time the presence of wind turbines in Indonesia is still very conventional and lack of control systems so that the electrical energy generated is still not optimal [1].

\subsection{Explore Importance of the Development Renewable Energy}

The continued development of the times, it also develops the technologies that can be used to design a wind turbine that generated electrical energy more optimal. One was the addition of the wind turbine control system. The purpose of the control system was added to the turbine is set rotational speed of the wind turbine shaft connected to the generator that has been rotated by the wind turbine will produce electrical energy [2].

\subsection{Describe Optimization Energy Using Control System}

One example of a widely used control system to optimize the rotational speed of the wind turbine blade angle is set in order to obtain optimum rotational speed. In addition, there is a much simpler control system and can also 
serve as a safety on the wind turbine system is speed control using brakes. The most important of this control system is to maintain the reliability of the generator because the generator specification is also worth noting that the rotation of wind turbines does not exceed the specifications of the generator that will reduce reliability even is damaged [3].

\subsection{Reliability Win Turbine System in Research Design}

To maintain the state of the generator can be used to keep long term and remain reliable, then additional automatic brake control system. In addition to maintaining the reliability of the generator, the control uses the brakes require less cost and easier to manufacture than control the angle of the blade. Control system will be made based on PD and Particle Swarm Optimization for the use of this control method can optimize the performance of wind turbine by selecting the proper tuning to the PD that is not too strong brakes if the brakes are too strong because it will weaken and the turbine wheel is difficult to be raised again. So expect the presence of the wind turbine control system has good performance and can improve efficiency $[3,4]$.

\section{Method}

PD- PSO block diagram shown in Figure 1. Models of PSO consists of a set of particles are initialized with a population of random candidate solutions [6]. They move through the dimensions of the problem space to search for new solutions, in which the fitness, $f$ can be calculated as a measure of quality for sure. Each particle has a position represented by a position vector $\mathrm{x}_{\mathrm{i}}(\mathrm{i}$, is the index of the particles) and speed (velocity) is represented by a vector velocity $v_{i}$. Each particle has so far given the best position ( $p$ best) in vector $x_{i l k}$ and the value of the $j$ the dimension is $\mathrm{x}_{\mathrm{ijk}}$. The best position vector between it swarm so far ( $\mathrm{g}$ best) is stored in the vector $\mathrm{x}_{1}$, and the value dimension $\mathrm{x}_{\mathrm{jl}}$. During the iteration for time $(\mathrm{t})$, update the speed of the previous velocity to the new velocity is determined by equation-4. The new position is determined by the sum of the previous position and the new model.

PSO algorithm is established through the initial population of candidate solutions at random particles, the particles position and velocity of particles. The fitness value of each particle can be calculations. Furthermore, it is known locally best fitness, which is the best fitness value of each particle and the local best position is the best position of each particle. Do a comparison of the current fitness value with the previous fitness value. If the value is better than substitute the particle positions prior to his current position which has fitness good value. The fitness value becomes the basis of determining the next fitness value. Finding global best fitness value, which is the minimum value of the local best fitness. Determining the global best position, which is done by replacing each candidate particle solutions with local best position of particles that meet the requirements of global best fitness? Update the velocity and position updates. In the block diagram above shows that the PSO to get input from a set point (SP), error (e) and process Variable (PV). So the PSO will continue to seek the most excellent parameters so that the set point can be achieved and the smaller the error. And in addition to the block diagram above, the relationship between PD and PSO can be described in the following block diagram Figure 1. The index of performance that must be considered in the PSO tuning parameters proportional derivative (PD). Namely maximum overshoot, rise time and settling time, so the tuning parameters $\mathrm{Kp}$ and $\mathrm{Kd}$ in exis. The PSO algorithm should be arranged so the performance index of the objective function PSO to be achieved [6].

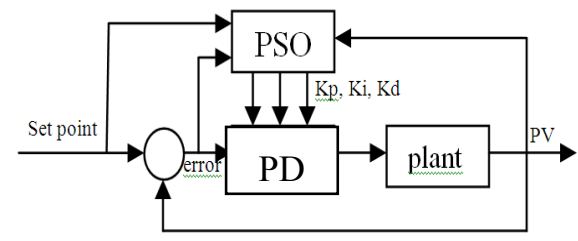

Figure 1. Block Diagram of PID-PSO Control System [6]

\subsection{Identify Automatic Brake Control System}

In this research, design and manufacture of automatic brake control system on wind turbine prototype-based PD-PSO begins with a study of the literature shows the characteristics and properties of the wind turbine including things that can affect the rotational speed of the wind turbine and control mode used is PD with parameters are determined by PSO. The next stage is the manufacture of automatic brake control system on the prototype wind turbine that includes the selection of the other components of hardware sensors, servo motors, and other discs which aims to get a good resolution of the motion and torque of the brake servo motors which will affect brake performance. Once the hardware is made, then the next stage is the initial data retrieval without 
using a controller that aims to determine the initial performance of the wind turbine. From the beginning of the data collection will be found the best angle to produce the maximum speed of the wind turbine.

\subsection{Software and Hardware Control Systems}

Controller design stage to design the PD controller based on PSO-based prototype of a wind turbine. In the controller design stage performed are divided into 2 controllers on the software and the hardware controller. The controller software includes a simulation that starts from the making of the transfer function of the plant, actuators and sensors then the transfer function of the particle swarm optimization. Once connected between the transfer function and the PSO program, it will get the PD parameters were then applied to the PD program then obtained system response. The design of the hardware controller must choose the appropriate components to get the best results as the selection of servo motors and also the methods used to drive the servo motor. The results obtained from the simulation parameters will be applied to the plant so that the response will be obtained according to the simulation.

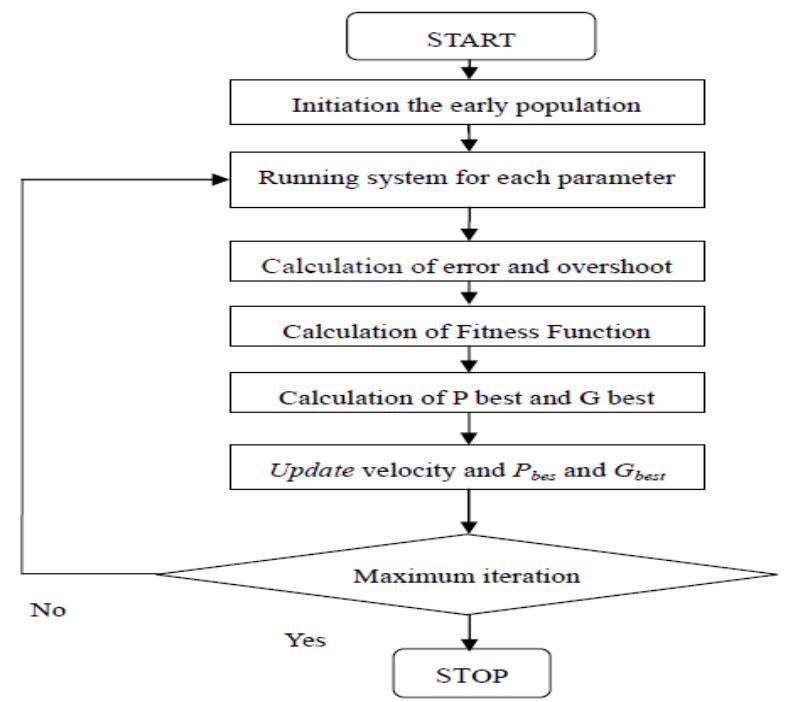

Figure 2. Algorithm of PD-PSO Control System

\subsection{Performance of Control System}

After the software and hardware to function properly the next step is testing and analyzing the performance of the control system. The testing phase is done by varying the set point. This stage aims to determine the performance of the control system has been designed. Design of Automatic Brake Control System, in the design of automatic brake control system through two phases: the design of software and hardware. In designing the software needed include the manufacture of wind turbine transfer function, program development and program PSO PD. For the development of the transfer function coefficients of performance refers to the following equation.

$$
C_{p}=1 / 2\left(\frac{\omega R}{v}-0.022 \beta^{2}-5.6\right) e^{-0,17 \frac{\omega R}{v}}
$$

From the above equation can be derived as follows.

$$
\frac{\delta\left(2 C_{p}+0.65\right) e^{0.17 \frac{\omega}{v}}}{\delta \omega}=\frac{\delta \frac{\omega}{v}}{\delta \omega}
$$

Having made the transfer function of the plant from the above equation, we then need to be made the transfer function of the sensor and actuator through the following equation

$$
\begin{gathered}
\text { Gain }=\text { SP output } / \text { SP input } \\
\frac{G(s)}{H(s)}=\frac{\text { gain }}{\left(\tau_{s}+1\right)}
\end{gathered}
$$

2.3.1 Step of Design PSO and PD 
After obtaining the transfer function of the plant, then the transfer function is incorporated into computational software program that contains the PSO and PD. Next is the design of hardware brake control system that its design as contained in the following flowchart.

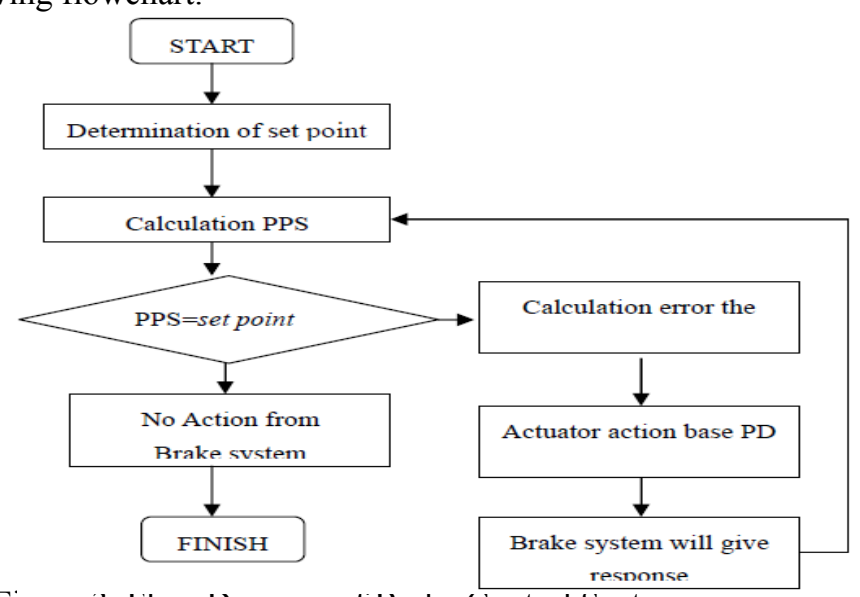

Figure 3. Flow Diagram of Brake Control System

\subsubsection{Set Point and Measures}

The flow diagram is representative of the programs that have been implanted on. The program begins by entering a set point value. Then the program calculates the number of pulses captured by the sensor rotary encoder per second (PPS). Furthermore PPS value compared to the value of the set point, if the set point value with the measured value at the corner of the brake system will not provide treatment. PPS If the value received from the sensor is not equal to the set point, the program will calculate the value of the error based on PD controller and then give the signal to the next servo motors servo motor will do to move the brake actuation system.

\subsubsection{Monitoring System}

The design of the monitoring system aims to determine the conditions that occur in the plant (wind turbines) in real time. This monitoring system is designed by using visualization software that has been associated with a microcontroller installed on a minimum system using serial communication. Explained that is done the first time that initializes the port used by matching ports between the computer and the microcontroller, then after the program starts, the computer will receive the data in the form of plant PPS error and then the data is displayed using visualization software such as Figure 4.

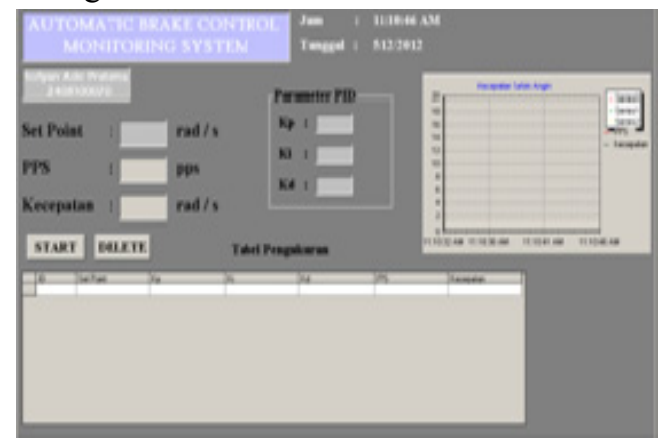

Figure 4. Display of Brake Control System [3]

\subsubsection{Experimental Manipulations or Interventions}

Here will be discussed about the tests performed on the system. The testing includes testing with simulations using computational software to get the parameters PD and also to get a response from the system. And also testing of a prototype automatic brake control system that includes testing actuators, and testing of prototype response generated by automatic brake control system as applied PD parameters based PSO. Test Response System against Influence and Effect of Number of Iterations Swarm.

\section{Results}

In testing using simulated using a computational software program to put PD-PSO parameters will be obtained 
and displayed the response of the system. Testing is done by giving a number of variations of the swarm and the number of iterations in the program swarm PSO is variation number is 20, 30, 40, 50 whereas the variation in the number of iterations is 25,50 and 75 .

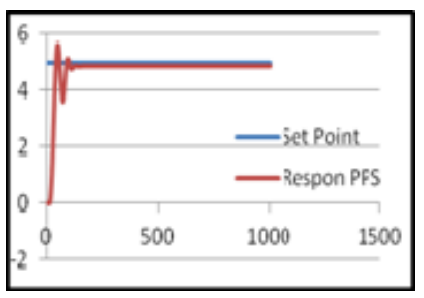

(a)

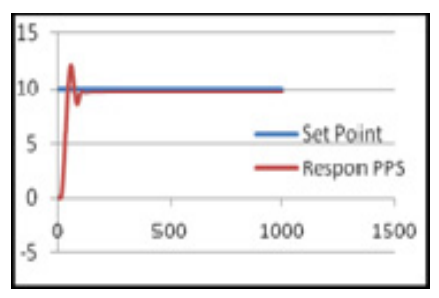

(b)

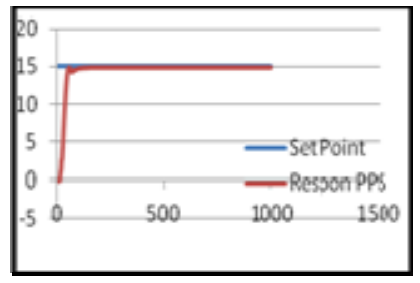

(c)

Figure 5. Response variation best of the swarm with a set number of points (a) 5 PPS, (b) 10 PPS, (c) 15 PPS

\subsection{Recruitment}

Provide dates defining the periods of recruitment and follow up and the primary sources of the potential subjects, where appropriate. If these dates differ by group, provide the values for each group.

\subsection{Statistics and Data Analysis}

Table 1 show that the number of the swarm does not have a major effect on the results of the response, although essentially the amount swarms effect. This is evidenced when the set point is obtained response 5 best in the swarm number 20, for set point 10 obtained the best response to the swarm number 40 and for set point 15 obtained the best results in the swarm number 50 .

Table 1. Performance of Swarm Variations

\begin{tabular}{lllllllr}
\hline Set point & Swarm & $\mathrm{Kp}$ & $\mathrm{Kd}$ & $\mathrm{Mp}$ & $\mathrm{Ts}$ & Error & Rate \\
\hline 5 & 20 & 0.3306 & 0.8724 & 6.5127 & 25.2 & 0.1060 & 4.893 \\
10 & 40 & 0.2238 & 0.6609 & 12.103 & 24.4 & 0.3101 & 9.689 \\
15 & 50 & 0.7147 & 2.0804 & - & 25.2 & 0.1488 & 14.847 \\
\hline
\end{tabular}

In Figure 6 and Table 2 are the best response results from experiments varying the amount of the swarm and the number of iterations? From the results of these experiments showed that the best results on the number of iterations 75. Results Figure 2 is taken on the best response when compared with the number of iterations 25 and 50. So from the above graph it can be seen that the major influence to get the best response is the number of iterations, although the number of the swarm will also affect the response to be generated because the more the number the faster the swarm to find the best response but it all depends on the initial state of the particle in the PSO program.

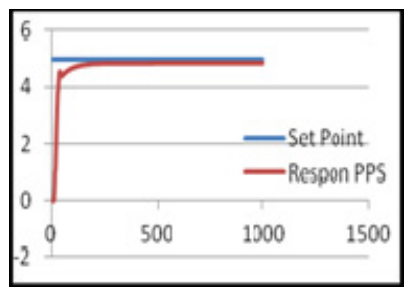

(a)

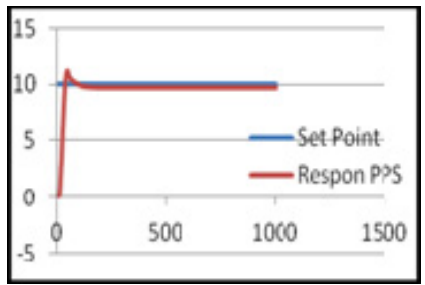

(b)

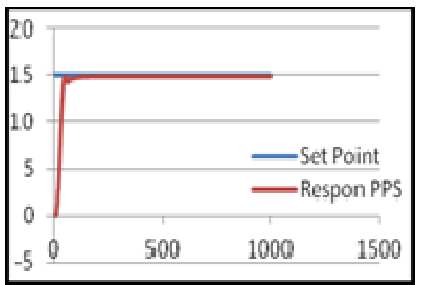

(c)

Figure 6. Response variations of iteration with set point (a) 5 PPS, (b) 10 PPS, (c) 15 PPS

In Figure 6 and Table 2 are the best response results from experiments varying the amount of the swarm and the number of iterations? From the results of these experiments showed that the best results on the number of iterations 75. Results Figure 2 is taken on the best response when compared with the number of iterations 25 and 50. So from the above graph it can be seen that the major influence to get the best response is the number of iterations, although the number of the swarm will also affect the response to be generated because the more the number the faster the swarm to find the best response but it all depends on the initial state of the particle in the PSO program.

In Figure 6 and Table 2 are the best response results from experiments varying the amount of the swarm and the number of iterations? From the results of these experiments showed that the best results on the number of iterations 75. Results Figure 2 is taken on the best response when compared with the number of iterations 25 and 
50. So from the above graph it can be seen that the major influence to get the best response is the number of iterations, although the number of the swarm will also affect the response to be generated because the more the number the faster the swarm to find the best response but it all depends on the initial state of the particle in the PSO program.

Table 2. Performance of iteration variations

\begin{tabular}{cllllll}
\hline Set point (PPS ) & $\mathrm{Kp}$ & $\mathrm{Kd}$ & $\mathrm{N}$ & Bird Step & $\mathrm{Mp}(\%)$ & Error (\%) \\
\hline 5 & 0.2812 & 1.2459 & 50 & $\mathbf{7 5}$ & 9 & 3 \\
10 & 0.4738 & 0.6060 & 50 & 75 & 14 & 2 \\
15 & 0.7147 & 2.0804 & 50 & 75 & 17 & 2 \\
\hline
\end{tabular}

\section{Discussion}

Test Prototype Automatic Brake Control System, analysis of the response of the control system can be analyzed qualitatively and quantitatively. Qualitative analysis can be seen by observing the maximum overshoot, steady state error or settling time. Testing is done by giving the same set point as testing on simulated is worth 5 PPS, 10 PPS and 15 PPS. The set point value represents the value received by the sensor pulse per second.

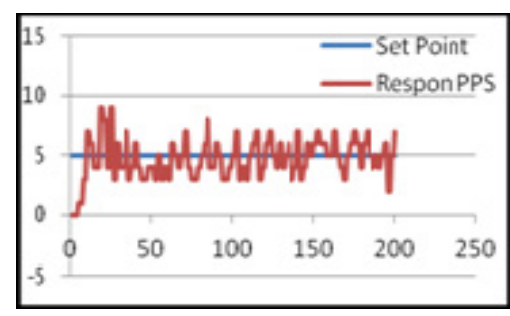

(a)

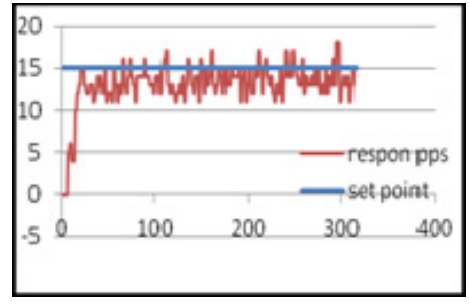

(b)

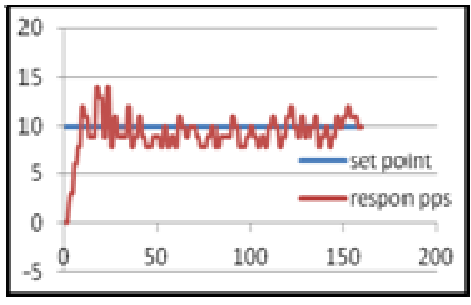

(c)

Figure 7. Response of Control System with Automatic Brake variations (a) 5 PPS, (b) 10 PPS, (c) 15 PPS

By set point 5 PPS seen that there are large oscillations occur because it is influenced by the state of the wind turbines are not balanced. When the set point is 10 PPS seen that the system is experiencing overshoot by 14 PPS when it happens because there is still a delay early runs between the signals sent by the sensor to the actuator. When it reaches steady overshoot is still there because there is still a delay between the sensors signals sent to the actuator but it has decreased from the first overshoot. While on the graph with set point 15 PPS at first did not experience overshoot due to reach the set point 15 requires great energy and turbine wheel is not too big, but when it reaches steady overshoot persists because of the delay despite a turbine wheel has begun a steady and large and system is still at the set point. Of the three above experiments it is known that the smaller the set point, the greater the oscillation occurs because this is the state of the wind turbines are not balanced, the more slowly the turbine wheel imbalance will be greater. The second cause of the oscillation is due to the delay between sending a signal to the actuator, causing the sensor response will be having overshoot.

Table 3. Performance of Control System with PSS Variation

\begin{tabular}{lllllll}
\hline Set Point (PPS) & $\mathrm{Kp}$ & $\mathrm{Kd}$ & $\mathrm{N}$ & Bird step & Mp (\%) & ESS (\%) \\
\hline 5 & 0.2812 & 1.2459 & 50 & 75 & 9 & 2 \\
10 & 0.4738 & 0.6060 & 50 & 75 & 14 & 2 \\
15 & 0.7147 & 2.0804 & 50 & 75 & 17 & 2 \\
\hline
\end{tabular}

To determine the performance of wind turbines, which must be known among other performance and power coefficient of the wind turbine? Observed relationship between wind speeds with coefficient of performance of wind turbines. When the set point 5 shows a graph of the oscillating this happens because when the set point 5 rounds too low so that the wind turbine imbalance will be even greater because of the condition of the wind turbine itself is not balanced and the performance of the largest wind turbine when wind speed of $7 \mathrm{~m} / \mathrm{s}$. As for set point 10 PPS coefficient of performance starts to increase due to the state of the wind turbines began to stabilize and for set point 15 when the wind speed is $2.8 \mathrm{~m} / \mathrm{s}$ wind speed there is no value behind the wind turbine but the overall coefficient of performance of wind turbines better.

\section{Conclusion}

Densign and development of brake control system based PD-PSO have conclusions the most influence on the results is a good response from the PSO with iterations variation, although the number of swarm too small 
though influential. Obtained the best results in the stimulation parameters, among others, on the set point 5 PPS parameters $\mathrm{Kp}$ and $\mathrm{Kd}=0.2812=1.2459$. To set point 10 obtained the best parameters are Kip $=0.4738$ and Kid $=0606$. As for set point 15 obtained the best parameters are Kip $=0.7147$ and $\mathrm{Kid}=2.0804$. The dynamic response of the plant is the best there is at set point 15. From the results of applying the above parameters of the response produced by the plant are due to delivery delays oscillation sensor signals to the actuators; this has led to overshoot the steady state. A unified tuning of PD-PSO controllers successfully carried out in this paper. PSO used to adjust the PD-PSO controllers. The proposed PD-PSO was compared with conventional generators in wind turbine plants. It showed that PD-PSO has a great effect on the system stability and performance system.

\section{References}

Bianchi, F. D., et al. (2007). Wind Turbine Control System. Germany: Springer Science + Business Media springer.com. http://dx.doi.org/10.1007/978-1-84996-353-4

Controller. International Journal of Engineering \& Technology IJET-IJENS, 10(05).

Kennedy, \& Beernaert, R. C. (1995). A New Optimizer Using Particle Swarm Theory. In Proceedings of the 1995 IEEE International Conference on Neural Networks. IEEE Service Center. Piscataway. http://dx.doi.org/0-7803-2768-3/95

Kennedy, J., \& Eberhart, R. (1995). Particle Swarm Optimization, Proceedings of the IEEE International Conference on Neural Networks, Perth, Australia, pp. 1942-1945. http://dx.doi.org/10.1109/ICNN.1995.488968

Kennedy, J., \& Eberhart, R. (2001). Swarm Intelligence, Academic Press, 1sted. San Diego, CA.

Mukherjee, V., \& Ghoshal, S. P. (2008). Particle swarm optimization-genetic algorithm based fuzzy logic controller for dual input power system stabilizers," J. Inst. Eng. India, pt. EL, 88, 36-43, Mar.

Mustafa, A. T. (2011). Design Optimal in Pitch-Controlled Variable-Speed under rated wind speed WECS using Fuzzy Logic Control. Canadian Journal on Electrical and Electronics Engineering, CJEEE, 2(6), 202-208. (ISSN: 1923-0540) June 2011.

Musyafa, A., et al. (2010). Pitch Angle Control of Variable Low Rated Speed Wind Turbine Using Fuzzy Logic.

Musyafa, A., et al. (2014). Design Control System of Pitch Angle Wind Turbine Horizontal Axis Based Imperialist Competitive Algorithm (ICA). International Journal of Scientific Research (IJSR), ISSN: 2277-8179

Rochmatullah. (2009). Modification Fuzzy Neuron Learning Vector Quantization using Particle swarm Optimization for Electronics sensing. Jakarta. Universities Indonesia.

Sayed, M. S., Boroujeni, R. H., Hamideh, D., \& Amin, S. B. (2011). Optimal PID power system stabilizer tuning based on particle swarm optimization. Indian J. Sci. Technol., 4(4), 379-383. Retrieved from http://www.indjst.org

Shi, Y., \& Eberhart, R. C. (1993). Empirical Study of Particle Swarm Optimization. Proc IEEE Inc Congr Evol Comput, (3), 1718-1727.

Sneckenberger, John, E., et al. (2003). Modeling and Control of a Wind Turbine as a Distributed Resource. IEEE.

Tony, B., David, S., Nick, J., \& Ervin, B. (2001). Wind Energy Handbook. New York. John Wiley \& Sons, Ltd.

Venter, G., \& Sobieski, J. (2002). Particle Swarm Optimization, AIAA 2002-1235, 43rd AIAA/ASME/ASCE/AHS/ASC Structures, Structural Dynamics, and Materials Conference, Denver, CO.

Ma,Y. C., Jiang, C. W., Hou, Z. J., \& Wang, C. M. (2004). The Formulation of the Optimal Strategies for the Electricity Producer Based On The Particle Swarm Optimization Algorithm". IEEE Trans Power System 2006, 21(4), 1663-1671. Singapore. http://dx.doi.org/10.1109/TPWRS.2006.883676

Zhang, J. Z., Cheng, M., Chen, Z., \& Fu, X. F. (2008). Pitch Angle Control for Variable Speed Wind Turbines. Journal DRPT Nanjing-China.

\section{Copyrights}

Copyright for this article is retained by the author(s), with first publication rights granted to the journal.

This is an open-access article distributed under the terms and conditions of the Creative Commons Attribution license (http://creativecommons.org/licenses/by/3.0/). 